In gatreral, differences among herds appeared to be the most important source of variation. Significant effects of year, month, and age at calving were also found for several diseases.

Differences between daughter groups were sigrificant for teat injuries, mastitis, any kind of teat or udiler disease, foot, leg, or locomotory diseases, veterinary treatments whatever the origin, and culling rate in the SRB breed, while only teat injuries, foot, leg, or locomotory diseases, and the veterinary treatments whatever the origin, were significant in the SLB breed. Heritability estimates varied between zero and $4.6 \mathrm{p}$. I00. The highest value was obtained for udder or teat diseases in SRB.

A difference of ro $\mathrm{p}$. roo in transmitting ability for veterinary treated daughters in first lactation was shown to exist between the extreme bulls within each breed, despite the fairly small number of bulls exceeding roo daughers, which was chosen as a minimum.

\title{
CLASSIC VS. DESIRED GAIN INDEX
}

\section{F. PIRCHNER}

\section{Lohrstuhl für Tievaucht der Technischen Universität München, Froising-Weihcnstephan}

Selection indices are among the most sophisticated tools of modern breeding theory. The optimal utilization of information leads to maximum gains in a given situation. However, extent and kind of information can be changed. The genetic change in milk and beef performance depends to a large extent on the resources allocated to estimate breeding values of the two respective trait complexes.

Desired gain index, suggested by Pezek and Baker, can take this problem into account and bring about changes in desired proportions. In view of the fact that agreement between supply and dimand is of paramount importance to overall efficiency of the economy, it appears that application of such techniques to achieve gains of various traits in correct proportions, deserves attention.

\section{NONLINEAR MODELS DESCRIBING THE DIFTERENCE, IN GROWTII CURVES OF CATTLE STRAINS}

$$
\text { Hiwa PTAK }
$$

\section{Department of Genetics and Animal Breeding Agricultural Academy, Krakow/Poland}

Five growth models fitted to the weight-age data of $F_{1}$ bull calves from to different Friesian strains, were compared for their suitability to discribe the shape of the growth curve. The most accurate model was Richards function followed by the von Bertalanffy, Gompertz, logistic and Brody functions. All models underestimated the I $7^{-1} 8$ month weights. The only significant differences between strains in growth parameters were found with the von Bertalanffy model.

\section{INVESTIGATIONS ON THE, INDIVIDUAL AND MATERNAI, COMPONENTS OF CALVING PERIORMANCE IN CATTLE}

\section{W. SCHLOTE, H. HÄSSIG, M. MUNZ und T. HOLZER}

\section{Institute of Animal Husbandry and Breeding, Hohenheim University Stuttgart (FRG}

The importance of the individual and maternal components of calving performance in a population of German Simmental cattle were to be studied and genetic parameters were to be estimated using the model of WiLLHAM. Calving data of calves of testing bulls for analysis of the individual component were collected in the first phase by special recording. Frequencies for classes of calving performance were: i 8 p. I 00 without assistance, $35 \mathrm{p}$. I 00 with little assistance, $44 \mathrm{p}$. I oo with considerable assistance and $3 \mathrm{p}$. I oo surgical assistance. Heritability for the individual component was $h^{2}=.14$ with a considerable standard error because of the relatively small data set $\left(s^{2} h_{1}=-\mathrm{I}_{4}\right)$. In the second phase, daughters of the same testing bulls were recorded at their first calving. From these $I, 200$ he:fer calvings parameters for the maternal component will be estimated using also the data of the first phase. For the third phase, the interior pelvic measurements of the heifers are currently also recorded in order to study this component of the maternal effect in more detail. 